\title{
The Effect of Modified Diabetes Self-management Education and Support on Self-care and Quality of Life among Patients with Diabetic Foot Ulcers in Rural Area of Indonesia
}

\author{
Dedi Damhudi ${ }^{1 *}$, Nyoman Kertia ${ }^{2}$, Christantie Effendy ${ }^{3}$ \\ ${ }^{1}$ Department of Nursing, Health Polytechnic of the Pontianak Ministry of Health, Singkawang, Indonesia; ${ }^{2}$ Department of Internal \\ Medicine, Faculty of Medicine, Public Health and Nursing, Universitas Gadjah Mada, Yogyakarta, Indonesia; ${ }^{3}$ Department of \\ Medical Surgical, Faculty of Medicine, Public Health and Nursing, Universitas Gadjah Mada, Yogyakarta, Indonesia
}

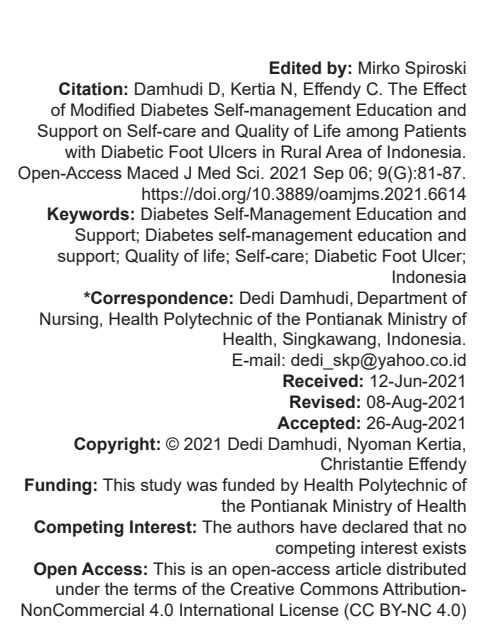

\section{Introduction}

Diabetes mellitus (DM) has become the greatest common metabolic disorder, with over 400 million people around the world suffering from it, as per a 2015 report by the International Diabetes Federation [1]. The proportion of people with diabetes is predicted to grow in the upcoming years [2], according to the latest projections. Indonesia has the fourth highest prevalence of diabetes in the world [3]. When comparing the prevalence of diabetes based on a proper diagnosis in the cohort aged 15 years and older in 2013 and 2018, the prevalence of diabetes increased to $2 \%$ in 2018 . The high blood sugar levels experienced by people with diabetes can result in small

\begin{abstract}
BACKGROUND: Diabetes self-management education and support (DSMES) programs are patient-centered holistic solution that enables it one of the best approaches for improving medication adherence enhanced coping empowerment and self-efficacy, quality of life (QoL), and lower rates of depression, in people with type 2 diabetes of diabetic foot ulcer (DFU).
\end{abstract}

Indonesian patients with DFUs.

METHODS: A quasi-experimental design with pre-test and post-test control group design, in Singkawang, West Kalimantan, Indonesia, with a total sample of 60 patients consisting of 30 patients in the intervention group and 30 patients in the control group. The DSMES has been adapted to cover $2 \mathrm{~h}$ of content for a period of 8 weeks appropriate nature similarities, such as a prominent change to represent changes in glucose counts; to incorporate photos; to incorporate culturally relevant eating habits, such as fish and fruit; to communicate in detail the significance of medication adherence, with an emphasis on metformin's organic, plant-based characteristics; and to emphasize engagement. Intention-to-treat analyses were conducted to determine the effect of modified DSMES on self-care, the control group at T1: In this study, (1) the DFU degree increased by $3.3 \%$ points $(95 \%$ confidence interval [Cl] $0.018-0.194),(2)$ the diabetes foot self-care behavior score increased by a modest $8.8 \%$ points $(95 \% \mathrm{Cl}: 0.021-0.203$ )

CONCLUSION: The primary outcome analyses indicate that the adapted DSMES was more effective than standard care at improving self-care and QoL and decreasing DFU degree in this sample of Indonesians with DFU, both immediately after and 3 months after the intervention. As nurse educators, it is our responsibility to ensure that we evaluate all of the support options accessible to the patients in our care. blood vessels and nerves in the extremities. Diabetic neuropathy frequently results in foot problems and the amputation of the lower extremities (LEA). Neuropathy affects approximately $20-50 \%$ of diabetics, according to the American Diabetes Association [4]. People with diabetes are $15-25 \%$ more likely than the general population to develop a foot ulcer [5]. Diabetic foot ulcers (DFUs) cause morbidity and, in some cases, permanent disability in diabetics [6], [7]. Lower extremity ulceration and amputation are associated with an increased risk of death [8], while significant amputation is associated with death [9], [10].

Quality of life (QoL) is a significant outcome of health and is a major concern when caring for a variety of patients, as well as those with diabetes. The reason for this is that one of the most serious 
consequences of diabetes is its negative impact on patients' QoL. According to the guidelines of the World Health Organization, a patient's specific perspective is concerned with the cultural identity and valuation of the society and the relationship between that person and its objectives, desires, requirements, and standards ([paragraphs 1-5]) [11], [12], [13]. DFU is also correlated with decreased QoL, particularly when it persists or worsens. Much research has been conducted to increase the QoL of DFU patients by analyzing the potential risks for impaired QoL and providing guidelines for the diagnostic, therapy, and care of DFU patients.

Patients with diabetes are responsible for providing $99 \%$ of their care [14]. Individual selfcare can be characterized as a set of personal behavioral modifications that are thorough, explicit, and educational [15]. Dietary management, treatment adherence, physical activity, blood glucose control, and foot care are all critical components of diabetes selfcare. However, this action has gone unnoticed, even though it is a large element of awareness [16]. When it comes to diabetic patients, self-care of the feet is not commonly practiced [17]. Previous studies found that the majority of older people with diabetes do not perform foot self-care due to problems associated with aging or because they have a neurocognitive impairment [18], [19]. Foot self-care can be regarded to be a solitary activity [20].

Diabetes self-management education (DSME) has long been recognized as a critical component of diabetes treatment outcomes [21]. In contrast to the traditional distinction between diabetes self-management education and support (DSMES) programs, Haas et al. [22], Beck et al. [23] proposed a combined definition for DSMES as "the continuous issue of enabling the understanding, abilities, and share characteristics for diabetes self-care, in addition to practices that aid an individual in establishing and maintaining the behavior." Dietary supplements, therapy, glycemic control, and other psychological aspects of therapy have all been used in the DSMES, and all have also been shown to be correlated with better health outcomes and lower hospital expenses [24]. DSMES is a patient-centered, holistic solution that enables it one of the best approaches for improving patients' medication adherence.

Previous DSME programs have shown enhanced coping [25], empowerment and self-efficacy [26], [27], QoL [24], [27], [28], and lower rates of depression [29], [30], and diabetes-related anxiety [31], [32] in people with type 2 diabetes mellitus (T2DM). Individuals who receive DSMES may significantly improve compliance to diet and exercise goals [33], as well as a decrease in glycosylated hemoglobin (A1C) [27], [31] and a delay in the initiation and severity of diabetes complications [34], [35]. Efficient DSMES approaches can improve self-recognition and self-referencing by supporting and providing training that is sensible to personal health belief systems, cultural differences, existing reconnaissance, physical restrictions, emotional problems, social support, financial situation, and health history. In isolation, DSME strategies have not shown significant improvements to self-care and/or reduction of DFU. Diabetes educators must shift their attention from only providing "information" and "advice" to assisting persons in developing good self-management skills. Failure to appropriately selfmonitor can result in more complicated diabetes foot illness, unnoticed increasing infection, and eventually LEA. Thus, this study sought to determine the effect of modified DSMES on self-care, DFU severity, and QoL in rural Indonesian patients with DFUs.

\section{Methods}

\section{Study design}

A quasi-experimental design with pre-test and post-test control group design, in Singkawang, West Kalimantan, Indonesia, with a total sample of 60 patients consisting of 30 patients in the intervention group and 30 patients in the control group.

\section{Intervention}

The DSMES has been adapted to cover $2 \mathrm{~h}$ of content for a period of 8 weeks and the eight-core components of DSMES. The subject matter covered DSME clinical definition, types of diabetes, fundamental physiology, objectives for blood glucose control (glycemia, blood pressure, and cholesterol targets), emotional and stress management, management of healthy food, activities/training, pharmacology, blood glucose A1C self-monitoring, signs/symptoms/ treatment, hyperglycemia, and sickness (interpretation and target range).

The subject matter covered DSMES clinical definition, types of diabetes, fundamental physiology, objectives for blood glucose control (blood glycemia, blood pressure, and cholesterol targets), emotional and stress management, management of healthy food, activities/training, pharmacology, blood glucose A1C self-monitoring, signs/symptoms/treatment, hyperglycemia, and sickness (interpretation and target range). The curriculum was culturally adapted revised to incorporate culturally appropriate nature similarities, such as a prominent change to represent changes in glucose counts; to incorporate photos; to incorporate culturally relevant eating habits, such as fish and fruit; to communicate in detail the significance of medication adherence, with an emphasis on metformin's organic, plant-based characteristics; and to emphasize engagement. 


\section{Participants}

The sample in this study was patients with a DFUs. The study required participants to be between the ages of 19 and 65 , to have been diagnosed with T2DM by a physician during the previous 5 years, to have had no diabetes instruction from any health center, and to be able to communicate in Bahasa Indonesia. Clients with mental health or psychosocial difficulties (e.g., schizophrenia, bipolar illness, chronic depression, and anxiousness) that are unable to give written permission were excluded from the study.

\section{Instrument}

The self-administered questionnaire collected personal information, age, gender, education level, and household income. Clinical data including body mass index, insulin pattern treatment, and fasting blood glucose. The Wagner ulcer classification was used to classify foot ulcers, which were divided into five grades: Grade 1, superficial diabetic ulcer; Grade 2, extended ulcer (to the tendon, bone, or joint); Grade 3, deep ulcer with abscess or osteomyelitis; Grade 4, gangrene in a portion of the forefoot; and Grade 5, extensive gangrene of the foot (17). A 36-point short-form health survey evaluated the QoL of participants (SF-36). The SF-36 was translated into Bahasa Indonesia and contains 36 items addressing eight different dimensions of QoL. There was a different score and proportion for each item. The higher the participants' scores, the higher their QoL. The current study's reliability was 0.87 .

The Diabetes Foot Self-Care Behavior Scale (DFSCBS) will be used to assess diabetic foot care behavior in participants. The DFSCBS measures seven-foot self-care behaviors, which inspect the foot floor, to check toes, wash toes, toes, moisturize and inspect inside the shoes, and brake shoes. A 5-point Likert scale ( $1=$ never to $5=$ always) is used, with a maximum score of 35 . A higher score suggests that you are doing a better job of taking care of your feet. This tool has a reliability of 0.95 for 2 weeks and an acceptable internal consistency of (alpha of Cronbach = 0.73) (Chin and Huang, 2013). The current study's reliability was 0.81 .

\section{Procedure}

Ethical clearance was obtained before data collection from affiliated university (165/II.I.AU/KET. ETIK/S-1/VII/2018). Patients were informed about the research during their first visits to the clinic, and those who expressed an interest in participating accomplished a screening survey to measure whether they were eligible to participate. Written consents were given to those who agreed to participate in this study. Approximately 1 week after their initial appointments, all participants returned to the clinic to complete the questionnaires (pre-test). Following that, they took part in the first $2 \mathrm{~h}$ education session for 8 weeks, which used facilitated/interactive learning and a lecture style PowerPoint presentation with $Q$ and $A$ (didactic learning). The sessions were taught in a collaborative setting by the entire research team, which included both certified diabetes educators who had been received training and had previous expertise in both methods of teaching. Two months later, participants returned to reply to class questionnaires (post-test 1 ). The participants then returned 1 month later for standard follow-up consultations and completed the surveys a $3^{\text {rd }}$ time (post-test 2). Completing the questionnaire takes about $15 \mathrm{~min}$. The researcher went over the subject's responses to make sure there are no gaps in information that need to be filled up. For ethical reasons, the researcher shall keep the subject's data confidential using sealed envelopes.

\section{Data analysis}

Intention-to-treat analyses were conducted to determine the effect of modified DSMES on selfcare, DFU severity, and QoL in patients with DFUs in rural Indonesia. Participants in the intervention and comparison classrooms were compared using regression models that accounted for baseline levels of the dependent variable within a classroom. In this study, linear regressions with fixed effects were used to make estimates. All of the regressions had reliable standard errors, and all of the models took gender and grade into consideration. In a comparison of DI differences, variances between T0, and T1 and T2, and T1 for intervention and control group were estimated (difference in difference [DID]). All of the analyses were carried out using SPSS version 23.

\section{Results}

Table 1 presents descriptive statistics for selected baseline sociodemographic characteristics for experimental and control groups among survey

Table 1: Comparison of selected baseline characteristics of intervention and control participants $(n=30)$

\begin{tabular}{|c|c|c|c|}
\hline \multirow[t]{2}{*}{ Variables } & Experimental, $(n=30)$ & Control, $(n=30)$ & $p$-value \\
\hline & $\%$ & $\%$ & \\
\hline Age in year (Mean \pm SD) & $41.56 \pm 0.37$ & $40.08 \pm 0.82$ & 0.145 \\
\hline \multicolumn{4}{|l|}{ Gender } \\
\hline Male & $14(46.7)$ & $17(56.7)$ & \multirow[t]{2}{*}{0.307} \\
\hline Female & $16(53.3)$ & $17(56.7)$ & \\
\hline \multicolumn{4}{|l|}{ Education level } \\
\hline Below senior high school & $15(50.0)$ & $17(56.7)$ & \multirow[t]{2}{*}{0.114} \\
\hline Above senior high school & $15(50.0)$ & $17(56.7)$ & \\
\hline \multicolumn{4}{|l|}{ Household income } \\
\hline Below regional minimum salary & $131(58.2)$ & $121(55.0)$ & \multirow[t]{2}{*}{0.213} \\
\hline Above regional minimum salary & $94(41.8)$ & $99(45.0)$ & \\
\hline Body mass index, $\mathrm{Kg} / \mathrm{M}^{2}$ & $24.9 \pm 8.4$ & $24.0 \pm 7.0$ & 0.081 \\
\hline Fasting blood glucose, mg/dl & $112.6 \pm 23.9$ & $113.7 \pm 25.7$ & 0.205 \\
\hline \multicolumn{4}{|l|}{ Treatment pattern } \\
\hline Insulin & $12(40.0)$ & $10(33.3)$ & \multirow[t]{2}{*}{0.216} \\
\hline Oral & $18(60.0)$ & $20(67.7)$ & \\
\hline
\end{tabular}


respondents in the analytical sample. There were no statistically significant differences between the intervention and control groups (Table 1).

Table 2 shows the baseline, T1 and T2 mean for the major indicators of interest, such as DFU degree, diabetes foot self-care behavior, and QoL, for each study group in the analytical sample. Respondents had middling levels of DFU degree at the time of the survey, with an average score of 2.35 (standard deviation $=0.74$ ). DFU degree decreased overtime, with participants in the intervention groups scoring 1.29 (standard deviation $=1.87$ ) at round $\mathrm{T} 2$, and responses were received in the control arm having scored 2.19 (standard deviation $=1.50$ ) at round T2. Diabetes foot self-care behavior improved overtime, with participants in the intervention groups scoring 33.7 $(S D=10.3)$ and participants in the control arm scoring $27.4(\mathrm{SD}=8.77)$ at round $\mathrm{T} 2$. At round T2, respondents in the intervention groups scored 130.5 (standard deviation $=30.9$ ), while respondents in the control arm scored 125.1 (standard deviation = 37.36). QoL improved overtime as respondents in the intervention groups scored 130.5 (standard deviation $=30.9$ ) and respondents in the control arm scored 125.1 (standard deviation $=37.36$ ).

Table 2: Outcomes among analytical sample, by intervention and control group and by survey

\begin{tabular}{lll}
\hline Variables & $\begin{array}{l}\text { Experimental, }(\mathrm{n}=225) \\
\text { Mean } \pm \text { SD }\end{array}$ & $\begin{array}{l}\text { Control, }(\mathrm{n}=220) \\
\text { Mean } \pm S D\end{array}$ \\
\hline Diabetic foot ulcer degree & & \\
$\quad$ Baseline & $2.35 \pm 0.74$ & $2.17 \pm 1.41$ \\
T1 & $3.12 \pm 0.53$ & $2.34 \pm 1.63$ \\
T2 & $4.29 \pm 1.87$ & $2.92 \pm 1.50$ \\
Diabetes foot self-care behavior & & \\
$\quad$ Baseline & $25.1 \pm 8.12$ & $26.7 \pm 7.15$ \\
T1 & $28.6 \pm 9.34$ & $26.5 \pm 9.40$ \\
T2 & $33.7 \pm 10.3$ & $27.4 \pm 8.77$ \\
Quality of life & & \\
Baseline & $124.1 \pm 25.93$ & $123.9 \pm 27.13$ \\
T1 & $126.7 \pm 26.12$ & $124.6 \pm 32.45$ \\
T2 & $130.5 \pm 30.9$ & $125.1 \pm 37.36$ \\
\hline
\end{tabular}

Table 3 shows the intent to treat estimates for each of the results of interest. The DSMES program improved outcomes in three of the three outcome indicators when compared to the control group at T1: In this study, (1) the DFU degree increased by $3.3 \%$ points (95\% confidence interval [CI]: 0.018-0.194), (2) the diabetes foot self-care behavior score increased by a modest $8.8 \%$ points $(95 \% \mathrm{Cl}: 0.021-0.203)$, and (3) the QoL increased by $32.7 \%$ points $(95 \%$ Cl: 00.075-0.689). The degree of DFU (DID coef. $0.350,95 \% \mathrm{Cl} 0.084-0.572)$, diabetes foot self-care behavior (DID coef. $0.085,95 \% \mathrm{Cl} 0.065-0.405$ ), and QoL (DID coef. 0.343, 95\% Cl 0.078-0.436) are all still significantly improved compared to the control at T2.

Table 3: Estimated DID for ITT

\begin{tabular}{lll}
\hline Variables & T1 & T2 \\
& DID coefficient $(95 \% \mathrm{Cl})$ & DID coefficient $(95 \% \mathrm{Cl})$ \\
\hline Diabetic foot ulcer degree & $0.093^{*}(0.018-0.194)$ & $0.350^{*}(0.084-0.572)$ \\
Diabetes foot self-care behavior & $0.088^{* *}(0.021-0.203)$ & $0.085^{* *}(0.065-0.405)$ \\
Quality of life & $0.327^{* *}(0.075-0.689)$ & $0.343^{*}(0.078-0.436)$ \\
\hline All models adjust for age; ${ }^{* * *} \mathrm{p}<0.001,{ }^{* *} \mathrm{p}<0.01,{ }^{*} \mathrm{p}<0.05,{ }^{*} \mathrm{p}<0.1$. DID: Difference in difference, ITT: Intent to \\
treat, Cl: Confidence interval.
\end{tabular}

\section{Discussion}

Participants in the DSMES intervention experienced a small but statistically significant improvement in self-care, DFU degree, and overall QoL when compared to those who received usual care after 2 months. Numerous reviews of the above-mentioned results confirm that DSMES is, in fact, effective. Other studies indicate that DSMES adequate awareness enhanced functional health and self-efficacy, decreased psychiatric conditions, enhanced monitoring for DM complications and a variety of other factors related to cardiovascular system disorders, and better QoL [36]. This research has several promising consequences for patient decision-making and treatment plan, which are discussed further below. This study provides evidence for patients, families, and health-care professionals in Singkawang, West Kalimantan, to consider choosing (or providing) culturally adapted, family-focused DSMES. Furthermore, in the previous studies on the usefulness of culturally congruent DSMES, patients and other health-care decision-makers from many other cultures may choose to consider modified DSME as an option to traditional DSMES. More broadly, this research suggests that includes family members and cultural context in chronic disease self-management education could be beneficial. The modified DSMES intervention differed from the normal DSMES intervention in several ways. As a result, it is impossible to disentangle the effects of each cultural adaptation aspect on the outcome variables. Future research might look into the benefits of a culturally customized curriculum, delivery by a community health worker, delivery in the home, and family participation. Additional research is needed to see if participants in the modified DSMES arm improved their selfmanagement habits (e.g. regularly checking blood glucose, being physically active). Self-care behaviors are an important part of successfully treating type 2 diabetes, therefore, any variations in these behaviors between arms could help explain the considerable reductions in DFU degree, improved self-care, and improved QoL seen among people in the modified DSMES arm. Future studies should also gather and analyze cost-effectiveness data to determine whether the modified DSMES incurs additional expenses compared to the normal DSME and whether there are spillover advantages for relatives who engage. Professionals trained in the field of research delivered all instructional programs. The benefit of this method is that it avoids observer bias while also providing accurate information to the elderly. Although most of the providers were health and medical science trained, the person giving the program may come from a different background. Discussions, demonstrations, videotapes, brochures, handbooks, and newsletters were used to provide the educational programs in a group or one-on-one setting. 


\section{Study limitation}

One limitation of the study was the small sample of participants, so research results may not be generalizable to other health-care settings. Although there were no significant differences in the demographic characteristics of the two groups, they were not as evenly correlated by age as they could have been. Larger sample size may allow for more in-depth assessments of various modified DSMES approaches. Additional information about patient needs and expectations and on the long-term implications of a modified DSMES program may also be provided by conducting focus groups in short (3-6 months) and long (12-14 months) intervals. Other research has indicated that longer-term behavior changes may necessitate longer-term interventions (13, 17, 37-40). Self-reported questionnaires are more prone to validity issues and misclassification, and they are less precise than standardized questionnaires.

\section{Conclusion}

The primary outcome analyses indicate that the adapted DSMES was more effective than standard care at improving self-care and QoL and decreasing DFU degree in this sample of Indonesians with DFU, both immediately after and 3 months after the intervention. This study fills a significant void in the current body of knowledge regarding DSMES in several ways. To the best of our knowledge, this study is the first to show significant improvements in outcome measures in a Kalimantan community. This study adds to an increasing body of literature that finds that culturalmodified DSMES can improve self-care, QoL, and decline in DFU by statistically significant and clinically important. As nurse educators, it is our responsibility to ensure that we evaluate all of the support options accessible to the patients in our care. Critically, people who cannot effectively take care of themselves should receive adequate social care and support for daily foot inspections.

\section{Authors' Contributions}

\section{Data collection}

Dedi Damhudi.

\section{Data analysis and interpretation} Effendy.

\section{Drafting of the article}

Effendy.

Dedi Damhudi, Nyoman Kertia, and Christantie

\section{Critical revision of the article}

Effendy.

Dedi Damhudi, Nyoman Kertia, and Christantie

\section{Data Availability Statement}

The datasets generated during and/or analyzed during the current study are available from the corresponding author on reasonable request.

\section{Ethical Consideration}

Ethical permission was obtained prior data collection from the Institutional Review Board of the affiliated university.

\section{References}

1. Polikandrioti M, Vasilopoulos G, Koutelekos I, Panoutsopoulos G Gerogianni G, Babatsikou F, et al. Quality of life in diabetic foot ulcer: Associated factors and the impact of anxiety/depression and adherence to self-care. Int J Low Extrem Wounds 2020;19(2):165-79. https://doi.org/10.1177/1534734619900415 PMid:31973632

2. Kateel R, Augustine AJ, Ullal S, Prabhu S, Bhat R, Adhikari P Development and validation of health related quality of life questionnaire (Indian scenario) in diabetic foot ulcer patients. Diabetes Metab Syndr. 2017;11 Suppl 2:S651-3. https://doi. org/10.1016/j.dsx.2017.04.020

PMid:28576563

3. Kementerian Kesehatan RI Badan Penelitian dan Pengembangan. Hasil Utama Riset Kesehatan Dasar. Kementrian Kesehat Republik Indones; 2018. p. 1-100. https:// doi.org/10.14203/press.298

4. Boulton AJ, Vileikyte L, Ragnarson-Tennvall G, Apelqvist J. The global burden of diabetic foot disease. Lancet. 2005;366(9498):1719-24. https://doi.org/10.1016/ s0140-6736(05)67698-2

PMid:16291066

5. Frykberg R, Cook J, Simonson D. Epidemiology and Health Care Cost of Diabetic Foot Problems: Medical and Surgical Management; 2018. p. 3-17. https://doi. org/10.1007/978-3-319-89869-8_1

6. Dinker R, Pai SS. Diabetic foot ulcer-diagnosis and management. Clin Res Foot Ankle. 2013;1(3):1-9. https://doi. org/10.4172/2329-910x.1000120 
7. Jahromi MK, Ramezanli S, Taheri L. Effectiveness of diabetes self-management education on quality of life in diabetic elderly females. Glob J Health Sci. 2014;7(1):10-5. https://doi. org/10.5539/gjhs.v7n1p10

PMid:25560339

8. Guideline CP. Clinical Practice Guidelines 2009, Management of Type 2 Diabetes Mellitus. $4^{\text {th }}$ ed. Malaysia: Ministry of Health Malaysia; 2009.

9. Nather A, FRCS. Team approach for diabetic foot problems. Diabetes. 2007;1:3-6.

10. National Institute of Health. Turning Discovery Into Health; 2009.

11. Post MW. Definitions of quality of life: What has happened and how to move on. Top Spinal Cord Inj Rehabil. 2014;20(3):167-80. https://doi.org/10.1310/sci2003-167

PMid:25484563

12. Shaw K, Killeen M, Sullivan E, Bowman P. Disparities in diabetes self-management education for uninsured and underinsured adults. Diabetes Educ. 2011;37(6):813-9. https:// doi.org/10.1177/0145721711424618

PMid:22021026

13. Shekelle PG, Morton SC, Keeler EB. Costs and benefits of health information technology. Evid Rep Technol Assess (Full Rep). 2006;132:1-71.

PMid:17627328

14. Feinglos M, Bethel M. Type 2 Diabetes Mellitus: An EvidenceBased Approach to Practical Management. Berlin, Germany: Springer; 2008

15. Webber D, Guo Z, Mann S. Self-care in health: We can define it, but should we also measure it? Self Care J. 2013;4:101-6.

16. Mosnier-Pudar H, Hochberg G, Eschwege E, Halimi S Virally ML, Guillausseau PJ, et al. How patients' attitudes and opinions influence self-care behaviours in Type 2 diabetes. Insights from the French DIABASIS survey. Diabetes Metab. 2010;36(6):476-83. https://doi.org/10.1016/j.diabet.2010.08.004 PMid:20947405

17. Chin YF, Huang TT. Development and validation of a diabetes foot self-care behavior scale. J Nurs Res. 2013;21(1):19-25. PMid:23407334

18. American Diabetes Association. (4) Foundations of care: Education, nutrition, physical activity, smoking cessation, psychosocial care, and immunization. Diabetes Care. 2015;38:S20-30. https://doi.org/10.2337/dc15-s007 PMid:25537702

19. American Diabetes Association. Standards of medical care in diabetes-2015 abridged for primary care providers. Clin Diabetes. 2015;33(2):97-111. https://doi.org/10.2337/ diaclin.33.2.97

PMid:25897193

20. Ciechanowski P, Russo J, Katon W, von Korff M, Ludman E, Lin $E$, et al. Influence of patient attachment style on self-care and outcomes in diabetes. Psychosom Med. 2004;66(5):720-8. https://doi.org/10.1097/01.psy.0000138125.59122.23 PMid:15385697

21. Bartlett EE. Historical glimpses of patient education in the United States. Patient Educ Couns. 1986;8(2):135-49. https:// doi.org/10.1016/0738-3991(86)90085-6 PMid:10300924

22. Haas L, Maryniuk M, Beck J, Cox CE, Duker P, Edwards L, et al. National standards for diabetes self-management education and support. Diabetes Care. 2012;35:2393-401. https://doi. org/10.2337/dc12-1707

23. Beck J, Greenwood DA, Blanton L, Bollinger ST, Butcher MK, Condon JE, et al. 2017 national standards for diabetes self-management education and support. Diabetes Educ. 2017;43(5):449-64. https://doi.org/10.1177/0145721717722968 PMid:28753378

24. Cochran J, Conn VS. Meta-analysis of quality of life outcomes following diabetes self-management training. Diabetes Educ. 2008;34(5):815-23. https://doi.org/10.1177/0145721708323640 PMid:18832286

25. Thorpe CT, Fahey LE, Johnson H, Deshpande M, Thorpe JM, Fisher EB. Facilitating healthy coping in patients with diabetes: A systematic review. Diabetes Educ. 2013;39(1):33-52. https:// doi.org/10.1177/0145721712464400 PMid:23073967

26. Tang TS, Funnell MM, Oh M. Lasting effects of a 2-year diabetes self-management support intervention: Outcomes at 1-year follow-up. Prev Chronic Dis. 2012;9:E109. https://doi. org/10.5888/pcd9.110313

PMid:22677159

27. Steinsbekk $A$, Rygg $L \varnothing$, Lisulo $M$, Rise $M B$, Fretheim $A$. Group based diabetes self-management education compared to routine treatment for people with Type 2 diabetes mellitus. A systematic review with meta-analysis. BMC Health Serv Res. 2012;12:213. https://doi.org/10.1186/1472-6963-12-213 PMid:22824531

28. Cooke D, Bond R, Lawton J, Rankin D, Heller S, Clark M, et al. Structured Type 1 diabetes education delivered within routine care: Impact on glycemic control and diabetes-specific quality of life. Diabetes Care. 2013;36(2):270-2. https://doi.org/10.2337/ dc12-0080

PMid:23139374

29. Hermanns N, Schmitt A, Gahr A, Herder C, Nowotny B, Roden $M$, et al. The effect of a diabetes-specific cognitive behavioral treatment program (DIAMOS) for patients with diabetes and subclinical depression: Results of a randomized controlled trial. Diabetes Care. 2015;38(4):551-60. https://doi. org/10.2337/dc14-1416

PMid:25605812

30. de Groot M, Doyle T, Kushnick M, Shubrook J, Merrill J, Rabideau $\mathrm{E}$, et al. Can lifestyle interventions do more than reduce diabetes risk? Treating depression in adults with Type 2 diabetes with exercise and cognitive behavioral therapy. Curr Diab Rep. 2012;12(2):157-66. https://doi.org/10.1007/ s11892-012-0261-z PMid:22350739

31. Siminerio L, Ruppert K, Huber K, Toledo FG. Telemedicine for reach, education, access, and treatment (TREAT): Linking telemedicinewith diabetesself-managementeducationtoimprove care in rural communities. Diabetes Educ. 2014;40(6):797-805. https://doi.org/10.1177/0145721714551993 PMid:25253624

32. Fisher L, Hessler D, Glasgow RE, Arean PA, Masharani U, Naranjo D, et al. REDEEM: A pragmatic trial to reduce diabetes distress. Diabetes Care. 2013;36(9):2551-8. https://doi. org/10.2337/dc12-2493

PMid:23735726

33. Toobert DJ, Strycker LA, King DK, Barrera MJ, Osuna D, Glasgow RE. Long-term outcomes from a multiple-risk-factor diabetes trial for Latinas: ¡Viva Bien! Transl Behav Med. 2011;1(3):416-26. https://doi.org/10.1007/s13142-010-0011-1 PMid:22022345

34. Nathan DM, Genuth S, Lachin J, Cleary P, Crofford O, Davis $M$, et al. The effect of intensive treatment of diabetes on the development and progression of longterm complications in insulin-dependent diabetes mellitus. N Engl J Med. 1993;329(14):977-86. https://doi.org/10.1056/ nejm199309303291401 
PMid:8366922

35. Stratton IM, Adler AI, Neil HA, Matthews DR, Manley SE, Cull CA, et al. Association of glycaemia with macrovascular and microvascular complications of Type 2 diabetes (UKPDS 35): Prospective observational study. BMJ. 2000;321(7258):405-12 https://doi.org/10.1136/bmj.321.7258.405

PMid:10938048
36. Turner D, Luzio S, Gray BJ, Bain SC, Hanley S, Richards A, et al. Algorithm that delivers an individualized rapid-acting insulin dose after morning resistance exercise counters postexercise hyperglycaemia in people with Type 1 diabetes. Diabet Med. 2016;33(4):506-10. https://doi.org/10.1111/ dme.12870

PMid:26220149 